Gut, 1980, 21, 32-36

\title{
Intraepithelial lymphocytes in the jejunal mucosa of malnourished rats $^{1}$
}

\author{
H V L MAFFEI, M A M RODRIGUES, J L V DE CAMARGO, AND \\ A O CAMPANA \\ From the Departments of Paediatrics, Pathology, and Medicine (Nutrition Division), Faculdade de Medicina \\ de Botucatu, 18600 São Paulo, Brasil
}

SUMmARY Intraepithelial lymphocytes (IEL) have been counted in the jejunal mucosa of adult Wistar rats submitted to a protein-free diet for 84 days and of a control group receiving a $20 \%$ casein diet, in order to evaluate the effect of protein deprivation. Relative counts (IEL/100 epithelial cells), absolute counts (number of IEL per millimetre of muscularis mucosae), and the proportion of lymphocytes crossing the basement membrane have been evaluated. Both relative and absolute IEL counts were diminished but the proportion of crossing lymphocytes was greatly increased in the malnourished group. The low number of IEL seemed to be related to lymphatic vessel dilatation in the lamina propria. The possibly primary effect of malnutrition on IEL counts in our experimental model and the eventual role of the observed lymphatic dilatation have been discussed.

Quantifying the intraepithelial lymphocytes (IEL) in the jejunal mucosa may be helpful in the differential diagnosis of diarrhoeic disorders, as their number is increased in patients with coeliac disease, either untreated or after gluten challenge (Ferguson and Murray, 1971; Lancaster-Smith et al., 1975, 1976; Ferguson et al., 1976; Mavromichalis et al., 1976), in adults with tropical sprue (Montgomery and Shearer, 1974) and in some children with giardiasis (Ferguson et al., 1976) but normal in those with gastroenteritis (Ferguson et al., 1976). In order to verify the influence of poor nourishment on this parameter, however, only one series of children, whose IEL counts did not change after recovery, has been studied (Schwartz et al., 1974). As several factors, apart from nutritional conditions, interact in malnourished patients we decided to evaluate the effect of protein deprivation on IEL of the jejunum in experimental conditions.

\section{Methods}

Fourteen young adult, male, albino rats of the Wistar strain, 123 to 124 days old, weighing on average $308 \mathrm{~g}$, were placed in individual cages and maintained in a temperature-controlled room $\left(21^{\circ} \mathrm{C}\right.$ to $\left.23^{\circ} \mathrm{C}\right)$. They were then assigned to two

${ }^{1}$ Based on a paper presented at the 11th International Congress of Nutrition on 27 August 1978 in Rio de Janeiro, Brazil.

Received for publication 2 August 1979 groups: seven animals were fed a $20 \%$ casein purified diet ad libitum (age control group), and the other seven were submitted to a protein-free diet, rendered isoenergetic to the control diet by the addition of more corn starch (malnourished group), as previously described (Angeleli et al., 1978).

After 84 days the rats were decapitated and exsanguinated. Blood was collected in a heparinised tube and plasma protein concentration estimated as described by Henry (1964).

Portions for histological studies were obtained from the proximal jejunum and fixed in $10 \%$ formalin. The paraffin sections, $5 \mu$ thick, were PAS stained. The IEL lying between at least 500 epithelial cells along the villi were counted blindly by one of the authors (M.A.M.R.) in vertically orientated sections, through a Zeiss integrating disk with 100/25 points, and expressed as the number of IEL per 100 villous epithelial cells (relative IEL number), according to Ferguson and Murray (1971). IEL were counted in two distinct sites of the slide, whenever lymphatic dilatation was present in some of the villi, together with villi without such dilatation. Then, the final result was the mean of counts along at least 1000 epithelial cells.

The width and the number of epithelial cells of each examined villus was registered. The relation between the number of these cells per villus and the villus width in a constant length of mucosa $(1 \mathrm{~mm}$ of muscularis mucosae) enabled us to evaluate the 
mean absolute number of IEL per linear unit, based on the following:

$\frac{1 \mathrm{~mm}(1000 \mathrm{u})}{\text { mean villi width }}=$ no. villi $/ \mathrm{mm}$

no. villi $/ \mathrm{mm}$. mean no. $\mathrm{EC} /$ villus $=$ no. $\mathrm{EC} / \mathrm{mm}$

$\mathrm{X}=\frac{\mathrm{n} . \mathrm{no} . \mathrm{EC} / \mathrm{mm}}{100 \mathrm{EC}} \quad \begin{aligned} & \mathrm{X}=\text { mean absolute } \mathrm{no} . \mathrm{IEL} / \mathrm{mm} \\ & \mathrm{n}=\text { mean relative IEL number }\end{aligned}$ $\mathrm{EC}=$ epithelial cell

$\mathrm{X}=\frac{\mathrm{n}}{100 \mathrm{EC}} \cdot \frac{\text { mean no. EC/villu }}{\mathrm{s}} \cdot 1000 \mu$

$\mathrm{X}=\mathrm{n} . \frac{\text { mean no. } \mathrm{EC} / \text { villus }}{\text { mean villi width }} .10$

Lymphocytes crossing the basement membrane were expressed as a percentage of the number of IEL plus crossing lymphocytes.

Student's $t$ test (Steel and Torrie, 1960) was used to test levels of significance at the $95 \%$ confidence level, for final body weight, plasma protein concentration, and IEL/100 epithelial cell counts.

\section{Results}

Rats given the protein-free diet for 84 days appeared apathetic, had pale ears and tails, and exhibited hair loss over perigenital areas and neck. Some of them had a sticky exudate over the eyelids, which remained closed most of the time. They did not develop diarrhoea during the experimental period. One rat in the malnourished group died on the 79th day of the experiment. Rats in the control group gained body weight (mean final weight $402.5 \pm 14.8 \mathrm{~g}$ ), whereas those in the proteindeficient group lost weight (mean final weight $164.0 \pm 11.5 \mathrm{~g}$ ) so that the final mean body weight of the protein deficient group was significantly lower than that of the control group. Plasma protein levels in rats given the protein-free diet were significantly lower $(4.4 \pm 0.3 \mathrm{~g} / 100 \mathrm{ml})$ than those in rats fed the $20 \%$ casein diet $(7 \cdot 0 \pm 0 \cdot 2 \mathrm{~g} / 100 \mathrm{ml})$.

In all the rats that were studied the majority of the IEL were localised in the basal part of the epithelium, as previously described (Darlington and Rogers,

Table Data in control and malnourished groups

\begin{tabular}{lcc}
\hline Measurement & Control group* & Malnourished group* \\
\hline IEL/100 EC $\dagger$ & $17 \cdot 8 \pm 5 \cdot 3$ & $11 \cdot 2 \pm 7 \cdot 08$ \\
Villus width $\dagger$ & $85 \cdot 8 \pm 11 \cdot 9$ & $74 \cdot 4 \pm 13 \cdot 3$ \\
EC/villus $\dagger$ & $177 \cdot 6 \pm 43 \cdot 1$ & $154 \cdot 8 \pm 37 \cdot 0$ \\
EC/mm & $2,070 \cdot 4$ & $2,077 \cdot 4$ \\
IEL/mm & $368 \cdot 1$ & $233 \cdot 3$ \\
$\%$ of crossing lymphocytes & $1 \cdot 6$ & $7 \cdot 0$ \\
\hline
\end{tabular}

* Diet for 84 days.

+ Results expressed as mean values $+S D$.

$\ddagger$ For calculations the readers are referred to the text (methods)

\$Malnourished group is significantly different from age control group at $\mathbf{P}<0.05$ by Student's $t$ test.

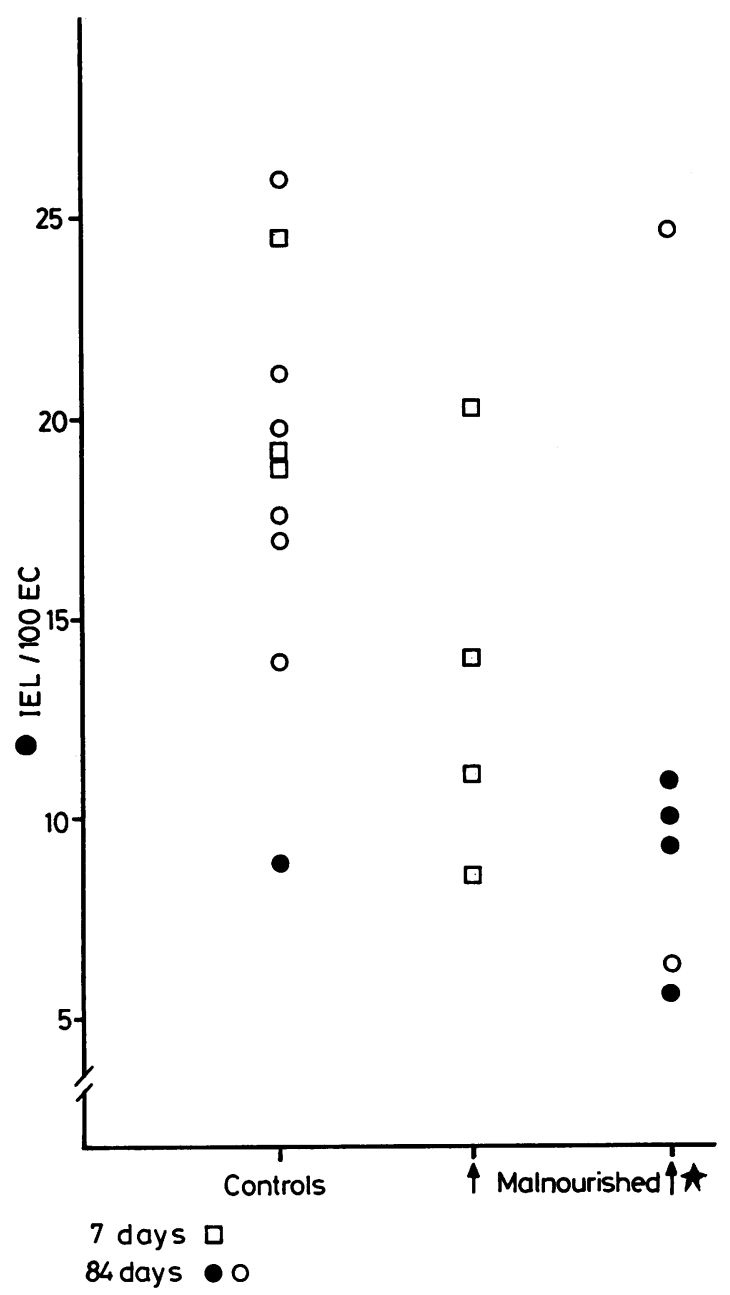

Fig. 1 Intraepithelial lymphocyte counts per 100 villous epitheliai cells in jejunal mucosa of rats after seven and 84 days of a protein-free diet and in matched controls receiving a $20 \%$ casein diet. Closed circles represent animals with lymphatic dilatation in the lamina propria. ${ }^{*} \mathrm{P}<0.05$ in relation to the 84-day control group.

1966; Meader and Landers, 1967). The IEL/100 epithelial cell counts were significantly lower in the 84-day malnourished rats than in the age control animals (Fig. 1, Table). This decrease was already suggested in a preliminary study, in which a small group of animals (included in Fig. 1) was killed after only seven days of a protein-free diet.

A variable dilatation of lymphatic vessels in the lamina propria was observed in four out of the six 84-day malnourished rats, but was present in only one of the control animals (Figs 1, 2a,b). For the 84-day groups, there was a relation between lymphatic dilatation and low IEL/100 epithelial cell 


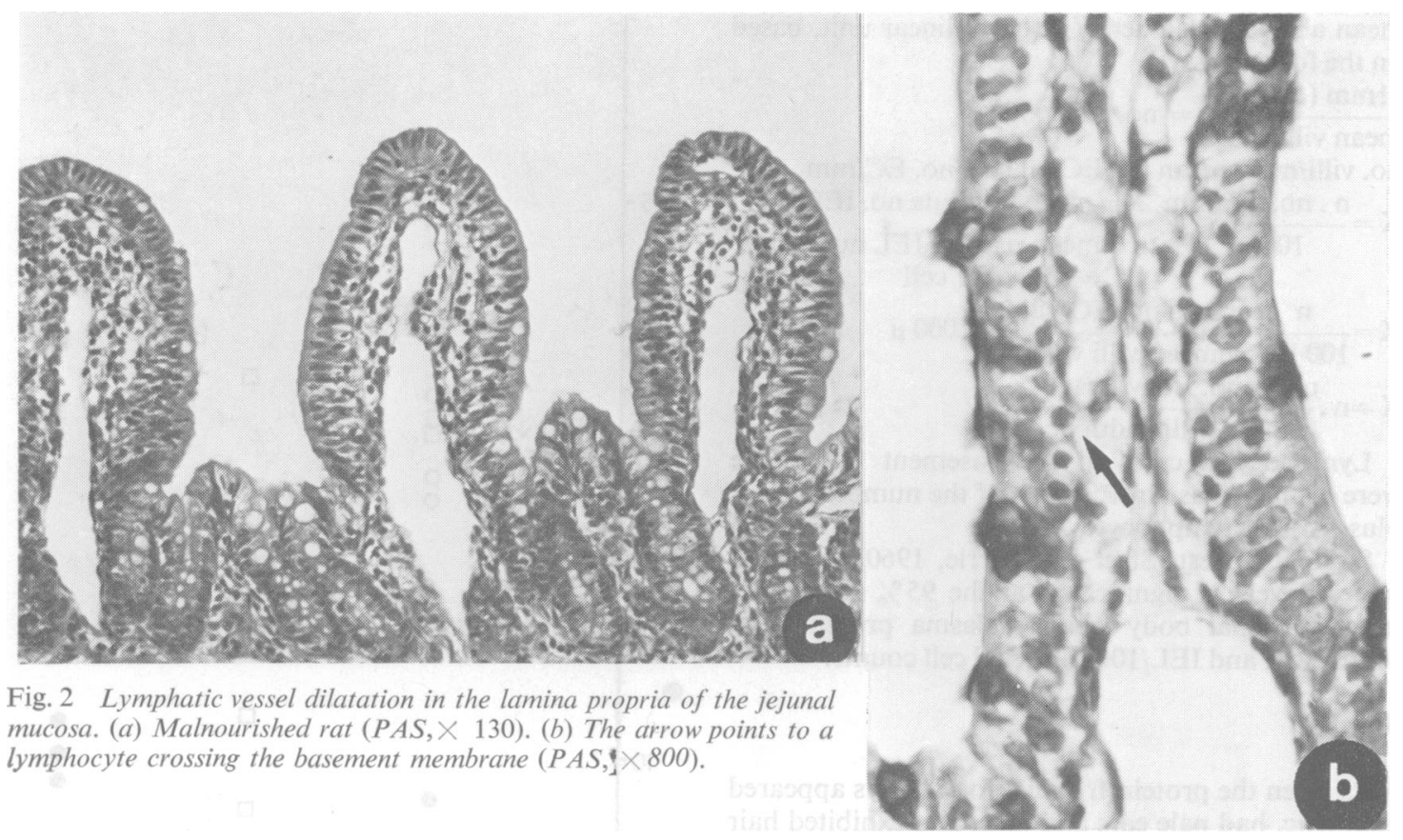

counts: whenever the dilatation was present-in one control and in four malnourished rats-a lower than 11.3 IEL count/100 epithelial cells was found; in contrast, the six control animals and one of two protein-deficient rats without such dilatation presented IEL counts/100 epithelial cells above 14 . In only one animal was this relationship not observed: a malnourished rat with 6.31 IEL/100 epithelial cells but without lymphatic abnormality (Fig. 1). For the seven-day groups this relationship was less evident because no animal presented a conspicuous lymphatic dilatation, but the two malnourished rats with the lowest IEC/100 epithelial cell counts had a slight dilatation in some villi.

Villus width and epithelial cell/villus are presented in the table, villi being narrower and the number of epithelial cell/villus decreased in the malnourished group. Absolute numbers of IEL, calculated as described in the methods section, were decreased as well (Table).

A more than fourfold increase in the proportion of crossing lymphocytes occurred in the malnourished group compared with the controls (Table).

\section{Discussion}

Our results showed a significant decrease in the relative number of IEL after 84 days of a proteinfree diet (the decrease being already apparent after only seven days of the diet) but, as villi were narrower in the malnourished group, a greater number of villi per linear unit of muscularis mucosae was present and this could counteract the decrease in the relative IEL counts. It was therefore essential to calculate the absolute number of IEL per millimetre of muscularis mucosae; this was obtained with no additional effort, as we applied a formula using the number of epithelial cells/villus, which was recorded along with the IEL/100 epithelial cell counts, and the villus width, which was measured through the same integrating disk as for the IEL counts and during the same procedure. Tissue shrinkage during inclusion in paraffin, of course, interferes with villus width, but this probably does not greatly affect the final results, as we used, for calculations, the mean value for villus width of the whole lot of animals of each group. These calculations confirmed the decrease in the IEL counts for the malnourished rats.

Intraepithelial lymphocytes of the small bowel are mainly thymus-derived $(\mathrm{T})$ lymphocytes, but their exact function is still unknown. One possible explanation for their location would be that the intestinal epithelium is an important site on the migration pathways of young $T$ cells, perhaps because of the large amounts of antigen which may be present in the intestinal lumen (Ferguson, 1977). Although data on antigen excess, either microbial or alimentary, are not available, it is known that germ- 
free animals deprived of microbial antigens have low IEL counts (Glaister, 1973; Ecknauer and Löhrs, 1976) and that removal of food antigen from healthy animals does not induce a decrease of IEL counts (Ferguson, 1976); on the other hand, it is suggested that the increase of IEL counts in coeliac disease must be due to antigen stimulation (Mavromichalis et al., 1976). It might be hypothesised, therefore, that an increase of intestinal IEL could be occurring in malnutrition, in which intestinal infection, bacterial overgrowth in the small bowel, or partial digestion of food protein antigens is likely to occur. But, as our malnourished rats were submitted to an extreme form of protein deprivation (a protein-free diet) and showed no sign of gastrointestinal infection, it is hardly likely that they received a greater antigen load. So, it might be held that in our work antigen stimulation was of less importance. In fact, a decrease in absolute and relative IEL counts was observed, supporting the idea that a primary effect of malnourishment on this parameter was involved, possibly reflecting the thymic atrophy observed in rats fed a protein-free diet (Aschkenasy, 1973). The interpretation of our results is not necessarily at variance with the data of Schwartz et al. (1974), who observed no increase in IEL counts in malnourished children after recovery; in this case, greater antigen stimulation during malnourishment could have increased a diminished IEL number due to malnutrition itself.

PAS stain allowed a good visualisation of the basement membrane, thus enabling the lymphocytes crossing the basement membrane to be easily distinguished (Fig. 2b). The percentage of crossing lymphocytes was greatly increased in the malnourished animals (Table), partly due to an increase in the number of crossing cells and partly due to the decrease of IEL, but, in our study, it was impossible to state whether the lymphocytes were crossing into or leaving the epithelium, because it is very likely that cells move in both directions (Meader and Landers, 1967). We must also draw attention to the striking relationship between the observed lymphatic dilatation in the lamina propria and low IEL counts (Fig. 1). This observation must be tested further in order to establish its true significance, because the route by which lymphocytes leave the epithelium is still a matter for debate; according to Ferguson (1977) it is likely, although not proven, that the IEL re-enter the lamina propria and leave the villi via the lymphatics.

In conclusion, it might be suggested that the decrease in IEL observed in the malnourished rats could be due to a reduced parent (thymic) population, of which IEL are a component, and that lymphocytes move faster around the body, as indicated by the greatly increased proportion of lymphocytes crossing the basement membrane. An additional decrease of IEL could be occurring because of a greater loss through the dilated lymphatic vessels, and, in this case, lymphocytes crossing the basement membrane would be preferentially leaving the epithelium.

\section{References}

Angeleli, A. Y. O., Burini, R. C., and Campana, A. O. (1978). Body collagen nitrogen in protein-deficient adult rats. Journal of Nutrition, 108, 1147-1154.

Aschkenasy, A. (1973). Role joué par l'atrophie du thymus dans les anomalies des réactions immunologiques contre les globules rouges de mouton (anticorps sériques, cellules a plaques et cellules a rosettes) chez rats carencés en protéines. Annales d'Immunologie, 124C, 345-362.

Darlington, D., and Rogers, A. W. (1966). Epithelial lymphocytes in the small intestine of the mouse. Journal of Anatomy, 100, 813-830.

Ecknauer, R., and Löhrs, U. (1976). The effect of a single dose of cyclophosphamide on the jejunum of specified pathogen-free and grem-free rats. Digestion, 14, 269-280.

Ferguson, A. (1976). Models of intestinal hypersensitivity. Clinics in Gastroenterology, 5, 271-288.

Ferguson, A. (1977). Intraepithelial lymphocytes of the small intestine. Gut, 18, 921-937.

Ferguson, A., McClure, J. P., and Townley, R. R. W. (1976). Intraepithelial lymphocyte counts in small intestinal biopsies from children with diarrhoea. Acta Paediatrica Scandinavica, 65, 541-546.

Ferguson, A., and Murray, D. (1971). Quantitation of intraepithelial lymphocytes in human jejunum. Gut, 12, 988-994.

Glaister, J. R. (1973). Factors affecting the lymphoid cells in the small intestinal epithelium of the mouse. International Archives of Allergy and Applied Immuno$\log y, 45,719-730$.

Henry, R. J. (1964). Proteins. In Clinical Chemistry: Principles and Technics, pp. 182-184. Hoeber Medical Division. Harper and Row: New York.

Lancaster-Smith, M., Kumar, P. J., and Dawson, A. M. (1975). The cellular infiltrate of the jejunum in adult coeliac and dermatitis herpetiformis following the reintroduction of dietary gluten. Gut, 16, 683-688.

Lancaster-Smith, M., Packer, S., Kumar, P. J., and Harries, J. T. (1976). Cellular infiltrate of the jejunum after re-introduction of dietary gluten in children with treated coeliac disease. Journal of Clinical Pathology, 29, 587-591.

Mavromichalis, J., Brueton, M. J., McNeish, A. S., and Anderson, C. M. (1976). Evaluation of the intraepithelial lymphocyte count in the jejunum in childhood enteropathies. Gut, 17, 600-603.

Meader, R. D., and Landers, D. F. (1967). Electron and light microscopic observations on relationships between lymphocytes and intestinal epithelium. American Journal of Anatomy, 121, 763-774. 
Montgomery, R. D., and Shearer, A. C. I. (1974). The cell population of the upper jejunal mucosa in tropical sprue and post infective malabsorption. Gut, 15, 387-391.

Schwartz, F. C. M., Chitiyo, M. E., and Wolfsdorf, J. (1974) Intraepithelial lymphocytes in the jejunum of malnourished children (Letter.) South African Medical Journal, 48, 2128.

Steel, R. G. D., and Torrie, J. H. (1960). Principles and Procedures of Statistics, pp. 73-75. McGraw-Hill: New York. 